\title{
Basic and low-risk substances under European Union pesticide regulations: a new choice for biorational portfolios of small and medium-sized enterprises ${ }^{1}$
}

\author{
Patrice A. Marchand* \\ Institut Technique de l’Agriculture Biologique (ITAB), 149 rue de Bercy, F-75595 Paris Cedex 12, France
}

Vol. 57, No. 4: 433-440, 2017

DOI: 10.1515/jppr-2017-0056

Received: August 8, 2017

Accepted: November 21, 2017

*Corresponding address: patrice.marchand@itab.asso.fr

\begin{abstract}
Directive 2009/128/EC of the European Parliament and of the Council of 21 October 2009 established a framework for Community action to bring about the sustainable use of pesticides and encourage low concern biorationals. Basic substances described in article 23 of EC phytopharmaceutical Regulation No 1107/2009 consist of a new operative category for crop protection products with 16 substances approved so far. Another status, ruled by article 22 is also operative with 11 approved low-risk substances (see EU pesticide database). Now small and medium-sized enterprises (SMEs) have the opportunity to register biorationals at the EU level in one of the two categories. Our institute previously provided technical expertise on how to complete the Basic Substance Application (BSA), together with a description of first results. However it is clear that there is a need for a shorter survey of the two parallel procedures for SMEs. Here we provide a concise sequence of the necessary steps for SMEs, including strategic approach, a rapid steps description, a timeframe for the global pathway, up to the final step, after approval by the Plants, Animals, Food and Feed Standing Committee (PAFF). We present in detail the advantages and limitations of the two statutes. The introduction of approved substances into organic farming is also discussed. Currently basic and low-risk substance pathways are now accessible for biorationals handled by SMEs. Therefore, the option is open for SMEs to seek a possibly low-risk active substances endorsement with market authorizations or a basic substance approval with no plant protection product claims depending on the selected strategy.
\end{abstract}

Key words: basic substance, biopesticides, EU regulation, low-risk substances, SMEs

\section{Introduction}

The growing economic importance of biopesticides and the requirements for environmentally viable solutions (EC 2009a) for plant protection led us to believe that "basic" and "low-risk" substance classes provide timely solutions for acceptance of Plant Protection Products (PPP). This especially applies to the majority of small molecules, light substances and biorational products (Czaja et al. 2015), which are mainly produced by small and medium-sized enterprises (SMEs).
Basic substances were recently described (Villaverde et al. 2014, 2016a; Marchand 2015, 2016) and references therein are a new category of EC phytopharmaceutical Regulation No 1107/2009 (EC 2009b) as a means of crop protection in agriculture alongside regular chemical active substances leading to plant protection products. The opportunity for approval of biorationals as "basic substances" at the European Union (EU) level is now operative (Marchand 2016) 
with the effectiveness of article 23 of EC Regulation No 1107/2009 (DGSanté 2017a). Similarly, low-risk substances managed by article 22 are effective with 11 approvals including three renewals (DGSanté 2017b), the latest being Coniothyrium minitans (EU 2017a). However, the choice between both pathways is of importance for SMEs and has to be considered carefully with all their various advantages and disadvantages.

\section{Definitions}

\section{Basic substance}

A basic substance is an active substance which is not a substance of concern; and does not have an inherent capacity to cause endocrine disruption, or have neurotoxic or immunotoxic effects. It is not predominantly used for plant protection purposes. Nevertheless, it is useful in plant protection either directly or in a product consisting of the substance and a simple diluent. It is not placed on the market as a plant protection product. In short, only the phytotherapeutic effect of a basic substance is recognised.

\section{Low-risk substance}

For microorganisms, an active substance which is a microorganism may be considered to be low-risk unless at strain level it has demonstrated multiple resistances to anti-microbials used in human or veterinary medicine. Baculoviruses shall be considered as being low-risk unless at strain level they have demonstrated adverse effects on non-target insects.

For active substances other than microorganisms, low-risk candidates should not be classified in accordance with Regulation (EC) No 1272/2008 as any of the following hazard statements: H200, H201, H202, H203, H300, H301, H310, H311, H317, H330, H331 H334, H350 H351, H340, H341, H360, EUH070, H370, H371, H400, or H410 (EC 2008a); or identified as a priority substance under Directive No 2000/60/ EC; or as an endocrine disruptor. They cannot exhibit neurotoxic or immunotoxic effects.

Persistence and bioconcentration factor criteria are set to 60 days/100, but for naturally occurring active substances, these values may be higher than these cut-offs.

\section{Pathway for selection between basic and low-risk categories}

A SME with biorationals in its portfolio can choose between either category. Details have to be expressed and clarified in order to choose and follow the most suitable procedure.

\section{Status}

Notwithstanding the benefits of the low-risk status, there is currently no direct way to ask for it in the initial application. Approvals as low-risk are granted by the EU Authority when the Plants, Animals, Food and Feed (PAFF) Committee votes. In contrast, basic substance status is not granted but claimed during direct application as "basic". It should be noted that the plant or animal origin of a substance does not confer the low-risk status automatically, nor that of the basic substance.

\section{Procedure}

The procedure and sequence for Dossier constitution, namely Basic Substance Application (BSA), is described in Sanco Guideline 10363/2012 rev.9 (DGSanté 2014a). Our institute later detailed the steps, course and issues for BSA (Marchand 2015, 2016). Note that products under food regulation (EC 2002) are intrinsic basic substances, thus chapter 5 on human health consideration is easier and shortened (Marchand 2016). Low-risk substances have been described previously (Villaverde et al. 2014, 2016a) and follow regular active substance (a.s.) processes under Regulation EC No $1107 / 2009$. The criteria are defined in article 22(3) and annex II.5, but will evolve according to precisions in a future Guidance Document on low-risk criteria (such as the one which is currently being developed for basic substances).

\section{Approval cost}

\section{Fees}

Evaluation fees are collected by national evaluation agencies, but can be reduced in certain Member States (M.S.) for biocontrol plant protection products. Total costs may reach 2-5 M€ with variable fees between Member States while evaluation of basic substances is free of charge (Skevas 2013; Marchand 2015).

\section{Additional costs}

Although the fee for basic substance evaluation is zero, most of the time due to bibliographic citation the applicant has to acquire corresponding articles in electronic file format and provide them for evaluation. Moreover, field trials are necessary to show utility of the substance; additional ecotoxicological studies may be required (i.e. soil leaching or bee tests). These costs are identical for both types of substances.

\section{Dossier}

Although a low-risk application is currently a full active substance application dossier, some parts may be 
reduced and waived in certain Member States depending on the substance profile (e.g. naturally occurring substances, microorganisms, pheromones). In contrast, BSA Dossiers are significantly easier compared to the mandatory mass of information requested for regular active substance registration.

\section{Bibliographic research}

As mentioned, for a regular active substance application, scientific peer-reviewed open literature assessment is obligatory for all active substances - article 8 (5) of Regulation (EC) No 1107/2009, therefore, bibliographic data are requested for the evaluation of basic substances (EFSA 2011). These are to be in larger quantity in order to estimate toxicological compartments found only in literature compared to regular calibrated in vitro trials. Foodstuffs to that respect are therefore obviously easier to evaluate with this approach. A complete dossier is required for low-risk potential active substances, but relief of fees may be granted by the Zonal Rapporteur Member State (ZRMS).

\section{Expected or believed efficacy}

Although low-risk substances are regular active substance with recognized efficacy, "utility" claimed for basic substances can be supported by effectiveness or regular efficiency tests with Abbott efficacy (i.e. for sugars). Indeed, most of the approved basic substances (vinegar, sugars, chitosan hydrochloride, calcium hydroxide, sodium bicarbonate, and other) show non-debatable effectiveness (Arnault et al. 2016; Marchand 2016).

\section{Timetable}

\section{Dossier constitution}

Submission of an active substance dossier may be done according to EU corresponding Guidelines (DGSanté 2014b; DGSanté 2016a, b). A dossier for potential low-risk substances is also a long process compared to relatively modest BSA Dossiers (e.g. 30-100 pages). Thus specifications and toxicological relevance of basic substances, especially intrinsic basic substances, require a modest volume of data. Institut Technique de l'Agriculture Biologique (ITAB) considers a timeframe of 2 to 3 months to prepare a BSA dossier while full active substance submission may take years.

\section{Toxicological and ecotoxicological issues}

Toxicological and ecotoxicological issues, together with environmental fate should also be considered. Modification of the criteria for microorganisms to achieve low-risk status takes these issues into account. Again, the environmental background of natural products may be taken into consideration. However, natural molecules or plant extracts are not automaticallygranted with the absence of risk, since even food products or substances of animal origin may have a negative environmental fate (for example, cow urine in streams and rivers).

\section{Admissibility}

The admission period between deposit at DGSanté and admissibility has not been considered recently (Villaverde et al. 2016a) for basic substances, but it could be perceived as an increasing delay before possible approval. However, similar delays are also observed for regular active substance applications, including for biocontrol agents (BCA).

\section{Evaluation}

The process after admissibility of the BSA takes more than 12 months, while for a low-risk regular PPP Dossier with all its volumes, complete evaluation of the zonal process requires years.

\section{Approval}

Prior to voting for the approval of an application, a draft is presented to the applicant with the option of correcting inaccuracies. Approval for both substances is done by the PAFF Committee with all 28 Member State representatives voting.

\section{Approval duration}

Approval for low-risk substances is granted for 15 years instead of 10 years for regular PPP active substances, while approval for an unlimited period of time for basic substances, is reviewable at any time by the EU (Villaverde et al. 2014).

\section{Approval area}

Basic substances are approved for the entire area of the EU while low-risk market authorizations may only be granted for one Zone (South, Middle or North) at maximum or nationwide at minimum.

\section{Market authorization and data protection}

Market authorization of derived products may protect approvals, but not in all situations. Competitors may deposit parallel market authorizations providing all requested data regarding active substances that are already approved. On the other hand, light registration as a "basic substance" does not protect the applicant from competitors selling the same basic substance (with identical specifications). While patented production of the substance is applicable in both cases, data protection from the BSA Dossier may be claimed via article 63 when submitting the application. According to article 28 of the PPP Regulation, the use at farm 
level for basic substance does not need market authorization, and according to article 23 (Part 1. Point $\mathrm{d}$ ) the same basic substance is not placed on the market as a plant protection product (EC 2009b). Marketing status for basic substances is therefore clearly definite at the EU level. This statement is clear for foodstuffs, available and not possibly sold as PPP, but some other basic substances like plant extracts are clearly sold as PPP in some M.S.

Market authorization of low-risk plant protection products derived from approvals protects the applicant's data. This process requires only 120 days.

\section{Maximum Residue Limit issues}

The Maximum Residue Limits (MRLs) of any active substance are not dependant on an applicant's choice but are settled by the EU and voted on by the PAFF Committee. Currently, analysis of pesticide residues is an important concern to fulfil the European Regulation (EC) No 1107/2009 (Villaverde 2016b). Low-risk substances usually show special and/or very particular physical and chemical properties/ characteristics that make their analysis difficult (i.e. microorganisms). Therefore, this important issue which is not always taken into serious consideration could be a criterion of choice between both low-risk and basic substances. Up to now, all basic substances are approved with subsequently no MRLs. Thus, all pesticide residue decisions concerning approved "basic substances" gave rise to the inscription in annex IV of regulation (EC) No 396/2005 (no MRL) a few months after approval (DGSanté 2015). A similar issue is observed with the first already approved low-risk substances as detailed in this specific guidance document on inclusion in the same annex IV, but may not be the case for subsequent low-risk substances. Therefore, this important criterion as a communication tool is not a criterion of choice between both pathways. Nevertheless, the ability of the substance to be considered as not requiring MRLs is a good indication of the suitability of the substance for approval as a basic substance.

\section{Transfer to organic farming plant protection annex}

\section{Direct transfer}

Food products of plant or animal origin approved as basic substances are directly entitled to be transferred to annex II of organic regulation (Marchand 2016, 2017a; EU 2016a). Regarding low-risk substances, due to the fact that most of them (8 out of the 11) are microorganisms, they are automatically allowed in organic farming.

\section{Inscription in the organic regulation}

If the transfer does not happen automatically following this new deposition, the corresponding application for inscription into annex II of organic regulation (EC 2008b) can be completed and submitted through the National Organic Farming authorities linked mainly to the EU Ministries of Agriculture. After a positive vote and approval as a "basic substance" under general pesticide regulation, the applicant may want to apply for the transfer of the "basic substance" to Organic Farming production, if a natural compound is involved. In order to enter organic production evaluation is required by Expert group for technical advice on organic production (EGTOP) (EC 2009c; Marchand 2016). The substance inclusion is later voted by the Regulatory Committee of Organic Production (RCOP) of DGAgri via QMV procedure (EU 2014a). The latest results about implementation of the basic substance in Organic Farming were recently described (Marchand 2017a). Low-risk substances, other than microorganisms, of natural origin (animal, mineral, vegetal) were authorized in organic production (i.e. ferric phosphate) or were submitted for inclusion with a good chance of insertion (i.e. COS-OGA and cerevisane) in annex II (EC 2008b).

\section{Strategy for selection between basic and low-risk approval pathways}

The regular approach for biocontrol agents as a pesticide is to follow the application and approval process under article 13 of RCE No 1107/2009. However, knowing the desire for the reduction of pesticidal impact, the need for a change in mode of action of the substances and the need for less toxic products, smaller molecules and common product uses are expected to increase in plant protection. These expectations, coupled with expected reduction of pesticides (EC 2009a) due to existing stress (EU 2015a) encourage more preventive crop protection products than curative ones. Thus, light compounds are expected to develop.

\section{Analysis of the substance}

Having in hand an effective biorational crop protection substance, the main question is accessibility of this substance. If anybody can access the substance freely, it is normally better to choose basic substance status. Numerous examples have been established, especially with foodstuffs or food additive products (Marchand 2016). Some submitted or approved basic substances are well known foodstuffs, such as sucrose, fructose, whey or lecithin. Others can be produced either via chemical 
Table 1. Eligibility criteria of basic and low-risk substances

\begin{tabular}{|c|c|}
\hline \multicolumn{2}{|c|}{ Eligibility criteria } \\
\hline basic substance (art. 23) & low-risk (art. 22) \\
\hline \multirow{7}{*}{ Not a substance of concern } & no carcinogenic \\
\hline & no mutagenic \\
\hline & no toxic to reproduction \\
\hline & no very toxic or toxic \\
\hline & no sensitising chemicals \\
\hline & no explosive \\
\hline & no corrosive \\
\hline \multirow{4}{*}{$\begin{array}{l}\text { Does not have an inherent capacity to cause endocrine } \\
\text { disrupting, neurotoxic or immunotoxic effects }\end{array}$} & no deemed to be an endocrine disrupter \\
\hline & no neurotoxic or immunotoxic effects \\
\hline & no persistent (half-life in soil is more than 60 days) \\
\hline & no bioconcentration factor is higher than 100 \\
\hline
\end{tabular}

Table 2. New cut-off criteria of low-risk substances

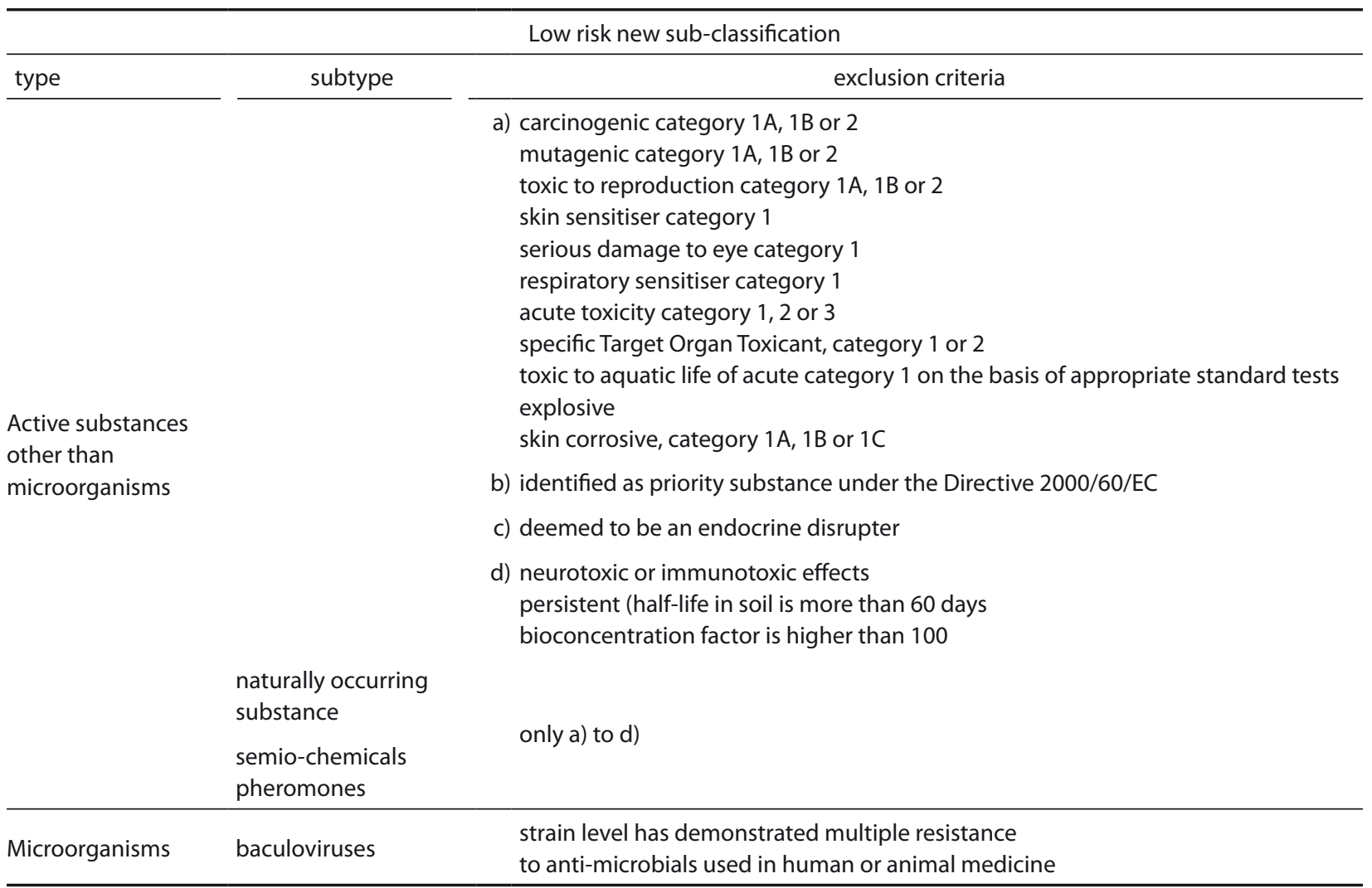

synthesis or through plant extraction (i.e. salicylic acid vs Salix cortex or vinegar vs acetic acid). In contrast, microorganisms are technically challenging to produce and to handle; they are intrinsically not submitted currently as basic substances although baker's yeast may be a good candidate. Light semiochemicals are eligible to be considered as basic substances, but more complex substances may need more complex evaluation even when they are employed as vapours, leading to no residues remaining in the final agricultural products.

\section{Criteria of eligibility}

Although the criteria and restrictions are obviously similar or identical, a few specific points are of importance as detailed in Table 1, with low-risk substances having more defined exclusion criteria. Clearly, a basic substance submitted with one non-acceptable characteristic in column 2 has a low chance of admissibility and less of approval, although a few examples may be of interest. Vinegar for instance, chemically comparable 
to $5-10 \%$ acetic acid in water was approved but is obviously corrosive, but as a foodstuff this criteria was not considered. Di ammonium phosphate persistence in soil is very long as a fertilizer, but this substance was considered as an attractant in traps, but not as a spray on crop production. This fact should be taken into consideration when applying a substance under PPP regulation.

\section{Evolution of the restriction criteria}

\section{For low-risk substances}

Recent EU modifications of the cut-off criteria (dispositions in annex II point 5 of the EC phytopharmaceutical Regulation No 1107/2009) for low-risk active substances were approved by the PAFF Committee in March 2017 (EU 2017c). These modifications are the second serious changes of this PPP regulation after Regulation 652/2014 and the deletion of article 76 (EU 2014c).

These adjustments allocated criteria for two distinct categories compared to initial considerations: microorganisms and active substances other than microorganisms. For chemical substances, initial criteria (Table 1) are retained. For the microorganism category, a new criterion of resistance to anti-microbials used in human or animal medicine has been added. For an active substance, other than a microorganism, a distinction is made between synthetic and naturally occurring active substances: either of animal, mineral, or vegetal origin or emitted by a natural source like pheromones or semiochemicals.

\section{For basic substances}

Approval of basic substances may be followed by an additional extension of uses request. An use extension application may end-up directly at the PAFF Committee for voting or it may be sent for evaluation to EFSA for a new outcome, especially when recipes or concentrations are changed. When an extension of uses is approved, an updated review report (RR) is published on the EU pesticide database.

\section{Conclusions}

The new PPP Regulation (EC 2009b) generated two new categories of "substances" besides the regular PPP. They need to be made more accessible to SME petitioners, in accordance with expectations for reduction of pesticide risk. The low-risk status is now obtainable with nine approvals in this category, although the qualification is not controlled nor claimed by the applicants. For the second new category of basic substances, following the first pilot projects, the approbation procedure is fully operational and the number of approvals (16) is increasing. This proves that policy changes due to societal demand can be efficiently implemented, including at the pesticide regulation level. Moreover, criteria for this new category may be a boost for biocontrol, non-biocide products or plant strengtheners, with rapid implementation at the field level.

Although some categories of biocontrol are difficult to envisage as basic substances due to the complexity of the molecules/substances, both ways may be followed by an applicant depending on the size and specifications of the substance. For these biorationals, clearly an application as a "basic substance" for a SME is cheaper and easier than application as a regular active substance, but with less or no protection. Given that only this category can be claimed at the submission stage by the applicant, the choice is difficult. In fact, because direct application as a Low-risk substance is currently not possible and low-risk status is not governable by the applicant, ITAB only recommends consideration of both application pathways looking at the substance specifications. This choice may also be a consequence of the analysis of already approved low-risk and basic substances. The list of basic substance candidates may also help (DGSanté 2014c). Indeed, ITAB considers that the two first newly approved "low-risk substances" (EU 2015c, d) could therefore have been approved as basic substances. With no MRL the two substances comply with technical and regulatory criteria of basic substances. They have a non-biocide status as elicitor or systemic resistance inducers. The third substance, ferric phosphates possess specifications acceptable for basic status. However, they are not accepted as "generally recognize as safe" (GRAS) but they are tolerated as a feed additive.

The final choice may also depend on potential money investment from SMEs and the availability the substance outside the plant protection area. Market authorizations may be futile and circumvented for a freely available substance. However, some applicants like a Member State or a third party (NGO, Associations) do not have that choice: regular application for an active substance is not readily accessible for them. Up to now SMEs choice concentrated on the active substance status, since basic substance status was not effective at the submission date of the corresponding applications.

Finally, both categories will undoubtedly expand in the next years.

\section{For basic substances}

In fact, two SMEs have already followed the basic substance pathway of approval for chitosan hydrochloride and clayed charcoal (EU 2014b, 2017a). This may be a signal for other applications from SMEs in the near 
future. In fact, many basic substance applications are currently under evaluation or are being prepared (DGSanté 2014b).

Among many positive approvals of basic substances (Marchand 2017b), quite a few applications were not successful. These rejected substances may be a source for low-risk substance applications in the future.

\section{For low-risk substances}

Looking at the profile of currently approved active substances, many low-risk substances may be granted with this status in the near future, and it is possible to list about a hundred potential candidates that will be reconsidered during the renewal application. Moreover, examining the profile of the current approved substances, quite few may also be granted with this status.

\section{Acknowledgements}

The author wishes to thank the French Ministry of Ecology: Direction Générale de la Prévention des Risques [V14 26-11-10, 2010-12] "PNPP”; Office National de l'Eau et des Milieux Aquatiques [17B "Biocontrol”], and [17B "PARMA"].

The author wishes to thank Dr. Trevor M. Fenning for providing helpful advice on the editing and writing of the manuscript.

\section{References}

Arnault I., Lombarkia N., Joy-Ondet S., Romet L., Brahim I., Meradi R., Nasri A., Auger J., Derridj S. 2016. Foliar application of microdoses of sucrose to reduce codling moth Cydia pomonella L. (Lepidoptera: Tortricidae) damage to apple trees. Pest Management Science 72 (10): 1901-1909. DOI: https://doi.org/10.1002/ps.4228

Czaja K., Góralczyk K., Strucinski P., Hernik A., Korcz W., Minorczyk M., Łyczewska M., Ludwicki J.K. 2015. Biopesticides - towards increased consumer safety in the European Union. Pest Management Science 71 (1): 3-6. DOI: https:// doi.org/10.1002/ps.3829

DGSanté. 2014a. Sanco Guideline 10363/2012-rev.9. Available on: https://ec.europa.eu/food/sites/food/files/plant/docs/ pesticides_ppp_app-proc_basic-subst_guidance.pdf

DGSanté. 2014b. SANCO/11470/2012-rev. 820 March 2014. Guidance document on botanical active substances used in plant protection products. Available on: https://ec.europa. $\mathrm{eu} /$ food/sites/food/files/plant/docs/pesticides_ppp_appproc_guide_doss_botanicals-rev-8.pdf. [Accessed: January $12,2017]$

DGSanté. 2014c. SANCO/10069/2013-rev.3. Available on: https://ec.europa.eu/food/sites/food/files/plant/docs/ pesticides_ppp_app-proc_basic-subst_list-candidates.pdf [Accessed: January 12, 2017]

DGSanté. 2015. SANCO/11188/2013-rev. 2 of 14.9.2015 Guidance document on criteria for the inclusion of active substances into Annex IV of Regulation (EC) No 396/2005. Available on: https://ec.europa.eu/food/sites/food/files/ plant/docs/pesticides_mrl_guidelines_sanco-2013-11188. pdf. [Accessed: January 12, 2017]
DGSanté. 2016a. SANCO/12545/2014-rev. 2; March 2016. Guidance document for applicants on preparing dossiers for the approval or renewal of approval of a micro-organisms including viruses according to regulation (EU) No 283/2013 and regulation (EU) No 284/2013. Available on: https://ec.europa.eu/food/sites/food/files/plant/docs/pesticides_ppp_app-proc_guide_applicants-microbial_en.pdf [Accessed: January 12, 2017]

DGSanté. 2016b. SANTE/12815/2014-rev. 5.2 May 2016. Guidance document on semiochemical active substances and plant protection products. Available on: https://ec.europa.eu/ food/sites/food/files/plant/docs/pesticides_ppp_app-proc_ guide_doss_semiochemicals-201605.pdf [Accessed: January 12, 2017]

DGSanté. 2017a. EU Pesticide Database. Available on: http:// ec.europa.eu/food/plant/pesticides/eu-pesticides-database/ public/? event=activesubstance.selection\&language $=$ EN then select "advanced search" and later select "type" "basic substances" [Accessed: January 12, 2017]

DGSanté. 2017b. EU Pesticide Database. Available on: http:// ec.europa.eu/food/plant/pesticides/eu-pesticides-database/ public $/$ ? event $=$ activesubstance. selection $\&$ language $=\mathrm{EN}$ then select "advanced search" and later select "type" "low-risk substances" [Accessed: January 12, 2017]

EC. 2000. Directive 2000/60/EC of the European Parliament and of the Council of 23.10.2000 establishing a framework for Community action in the field of water policy. Official Journal of the European Union L 327: 1-72.

EC. 2002. Regulation (EC) No 178/2002 of the European Parliament and of the Council of 28 January 2002 laying down the general principles and requirements of food law, establishing the European Food Safety Authority and laying down procedures in matters of food safety (1) (the Authority). It should be clarified that the Authority performs a risk assessment whilst the Commission should perform the risk management role and take the final decision on an active substance. Provisions should be included to ensure the transparency of the evaluation process. Official Journal of the European Union L 31: 1-24.

EC. 2008a. Regulation (EC) No 1272/2008 of the European Parliament and of the Council of 16.12.2008 on classification, labelling and packaging of substances and mixtures, amending and repealing Directives 67/548/EEC and 1999/45/EC, and amending Regulation (EC) No 1907/2006. Official Journal of European Union L 353: 1-84.

EC. 2008b. Regulation (EC) No 889/2008 of 5.9.2008 laying down detailed rules for the implementation of Council Regulation (EC) No 834/2007 on organic production and labelling of organic products with regard to organic production, labelling and control. Official Journal of European Union L 250: $1-84$.

EC. 2009a. Directive 2009/128/EC of the European Parliament and of the Council of 21 October 2009 establishing a framework for Community action to achieve the sustainable use of pesticides. Official Journal of the European Union L 309: 71-86.

EC. 2009b. Regulation (EC) No 1107/2009 of the European Parliament and the Council of 21 October 2009 concerning the placing of plant protection products on the market and repealing Council Directives 79/117/EEC and 91/414/EEC. Official Journal of the European Union L 309: 1-50.

EC. 2009c. Expert group for technical advice on organic production (EGTOP) established by Commission Decision 2009/427/EC of 23.4.2009 on the effort of Member States to reduce their greenhouse gas emissions to meet the Community's greenhouse gas emission reduction commitments up to 2020. Official Journal of European Union L 140: 136-148.

EFSA. 2011. European Food Safety Authority; Submission of scientific peer-reviewed open literature for the approval of pesticide active substances under Regulation (EC) No 1107/2009. EFSA Journal 9 (2): 2092. DOI: 10.2903/j. efsa.2011.2092. 
EU. 2014a. Qualified Majority system. Available on: http://europa.eu/legislation_summaries/glossary/qualified_majority_en.htm [Accessed: January 12, 2017]

EU. 2014b. Regulation (EU) 563/2014 of 2 3.5.2014 approving the basic substance chitosan hydrochloride. Official Journal of the European Union L 156: 5-7.

EU. 2014c. Implementing Regulation (EU) 652/2014 of 14.5.2014 laying down provisions for the management of expenditure relating to the food chain, animal health and animal welfare, and relating to plant health and plant reproductive material, amending Council Directives 98/56/EC, 2000/29/EC and 2008/90/EC, Regulations (EC) No 178/2002, (EC) No 882/2004 and (EC) No 396/2005 of the European Parliament and of the Council, Directive 2009/128/EC of the European Parliament and of the Council and Regulation (EC) No 1107/2009 of the European Parliament and of the Council and repealing Council Decisions 66/399/EEC, 76/894/ EEC and 2009/470/EC. Official Journal of European Union L 189: 1-32.

EU. 2015a. Implementing Regulation (EU) 2015/408 of 11.3.2015 on implementing Article 80 (7) of Regulation (EC) No $1107 / 2009$ of the European Parliament and of the Council concerning the placing of plant protection products on the market and establishing a list of candidates for substitution. Official Journal of European Union L 67: 18-22.

EU.2015b. Implementing Regulation (EU) 2015/543 of 1.04.2015 approving the active substance COS-OGA, in accordance with Regulation (EC) No 1107/2009 of the European Parliament and of the Council concerning the placing of plant protection products on the market, and amending the Annex to Commission Implementing Regulation (EU) No 540/2011. Official Journal of European Union L 157: 1-163.

EU. 2015c. Implementing Regulation (EU) 2015/553 of 7.4.2015 approving the active substance cerevisane, in accordance with Regulation (EC) No 1107/2009 of the European Parliament and of the Council concerning the placing of plant protection products on the market, and amending the Annex to Commission Implementing Regulation (EU) No 540/2011. Official Journal of European Union L 92: 86-88.

EU. 2016a. Implementing Regulations (EU) No 2016/673 of 29.4.2016 amending Regulation 889/2008. Official Journal of European Union L 116, 30.4.2016, p. 8-22.

EU. 2017a. Implementing Regulation (EU) 2017/842 of 17.5.2017 approving the low-risk active substance Coniothyrium mini- tans strain CON/M/91-08. Official Journal of the European Union L 125: 16-20.

EU. 2017b. Implementing Regulation (EU) 2017/428 of 10.3.2017 approving the basic substance clayed charcoal. Official Journal of European Union L 66, 11.3.2017, p. 1-3.

EU. 2017c. Implementing Regulation (EU) 2017/1432 of 07.8.2017 amending Regulation (EC) 1107/2009 of the European Parliament and the council concerning the placing of plant protection products on the market as regards the criteria for the approval of the low-risk substance. Official Journal of the European Union L 205: 59-62.

Marchand P.A. 2015. Basic substances: an opportunity for approval of low-concern substances under EU pesticide regulation. Pest Management Science 71 (9): 1197-1200. DOI: https://doi.org/10.1002/ps.3997

Marchand P.A. 2016. Basic substances under EC 1107/2009 phytochemical regulation: experience with non-biocide and food products as biorationals. Journal of Plant Protection Research 56 (3): 271-277. DOI: https://doi.org/10.1515/ jppr-2016-0041

Marchand P.A. 2017a. Basic substances under EU pesticide regulation: an opportunity for organic production? Organic Farming 3 (1): 16-19. DOI: 10.12924/of2017.03010016

Marchand P.A. 2017b. Basic substances as renewable and affordable crop protection products. Chronicle of Bioresource Management 1 (2): 065-066.

Skevas T., Oude Lansink A.G.J.M., Stefanou S.E. 2013. Designing the emerging EU pesticide policy: A literature review. NJAS - Wageningen Journal of Life Sciences 64-65: 95-103, DOI: $10.1016 /$ j.njas.2012.09.001

Villaverde J.J., Sevilla-Morán B., Sandín-España P., López-Goti C., Alonso-Prados J.L. 2014. Biopesticides in the framework of the European Pesticide Regulation (EC) No. 1107/2009. Pest Management Science 70 (1): 2-5. DOI: https://doi. org/10.1002/ps.3663

Villaverde J.J., Sandín-España P., Sevilla-Morán B., López-Goti C., Alonso-Prados J.L. 2016a. Biopesticides from natural products: current development, legislative framework, and future trends. BioResources 11 (2): 5618-5640. DOI: https://doi.org/10.15376/biores.11.2.villaverde

Villaverde J.J., Sevilla-Morán B., López-Goti C., Alonso-Prados J.L., Sandín-España P. 2016b. Trends in analysis of pesticide residues to fulfil the European Regulation (EC) No. 1107/2009. Trends in Analytical Chemistry 80: 568-580. DOI: https://doi.org/10.1016/j.trac.2016.04.017 